\title{
Comparative Study on Dyeing of Cotton, Modal and Lyocell Fabrics Using Bifunctional and Polyfunctional Reactive Dyes
}

\author{
Md. Ershad Khan \\ Department of Textile Engineering, Ahsanullah University of Science and Technology, Dhaka, Bangladesh \\ Email: ershad.dtt@aust.edu
}

How to cite this paper: Khan, Md.E. (2020) Comparative Study on Dyeing of Cotton, Modal and Lyocell Fabrics Using Bifunctional and Polyfunctional Reactive Dyes. Journal of Textile Science and Technology, 6, 40-48.

https://doi.org/10.4236/jtst.2020.61004

Received: November 16, 2019

Accepted: February 1, 2020

Published: February 4, 2020

Copyright $\odot 2020$ by author(s) and Scientific Research Publishing Inc. This work is licensed under the Creative Commons Attribution International License (CC BY 4.0).

http://creativecommons.org/licenses/by/4.0/

\begin{abstract}
Polyfunctional reactive dyes have been introduced by the renowned dye manufacturers in the recent years for better exhaustion and fixation performance. This paper deals with evaluation of the dyeing performance of three cellulosic fibres namely cotton, modal and lyocell with polyfunctional (Avitera Cardinal SE) reactive dye in comparison a bifunctional-(Novacron Brilliant Red FN-3GL) reactive dye. The purpose of this study is to achieve a better understanding of exhaustion and fixation behaviour in dyeing of cotton, modal and lyocell fibres using these two types of reactive dyes. The dyeing was carried out at four different shade $\%(1 \%, 2 \%, 3 \%$, and $4 \%)$. Besides studying exhaustion (\%) and fixation (\%) along with $\mathrm{K} / \mathrm{S}$ values of dyed fabrics, several other quality parameters e.g. bursting strength, pilling resistance and colour fastness to wash were also examined. Finally, the optimum combination among the three types of cellulosic fabrics and two types of reactive dyes was observed. Lyocell fabric and polyfunctional reactive dyes have been found more sustainable.
\end{abstract}

\section{Keywords}

Polyfunctional Reactive Dye, Exhaustion, Fixation, Cellulosic Fibre

\section{Introduction}

Cellulosic fibres are the most widely used raw material of textile industries. Among them natural cellulose cotton fibre is still mostly used [1]. To reduce the use of cultivation land some regenerated cellulosic fibres are invented where fast growing wood tree is used as primary raw material source. Viscose and lyocell are among them. Modal is a modified version of viscose having high wet tenacity and lyocell is the latest invention of regenerated cellulose [2]. 
From the ancient time, the oldest cellulosic fibre, cotton was dyed with the natural colourants [3]. From the late 19th century, application of synthetic dye was started. Among them, mainly direct and vat dye were applied on cotton dyeing with many limitations in processing and quality. With the development of reactive dyes in 1950s, the application of reactive dyes on cellulosic fibre increases rapidly. The first-generation reactive dyes for cellulosic fibre had lower exhaustion and fixation rate which was a great concern for its sustainability. A numerous research was conducted to increase its exhaustion and fixation rate. Bifunctional reactive dyes are one of the successful reactive dyes in this concern. But one of the latest developments of reactive dyes is polyfunctional reactive dyes which are being claimed more sustainable reactive dyes at present [4].

The dyestuff which is suitable for cotton is also applicable on regenerated cellulosic fibres. Though there are many similarities between cotton and other regenerated cellulosic fibres, there are also significant differences between these fibres. So, the dyeing performance of these fibres could vary [5].

Our aim is to establish a comparative study of dyeing performance cellulosic fibres (natural and regenerated) dyed with reactive dyes (bifunctional and polyfunctional) in terms of exhaustion\% and fixation\% along with other quality parameters to identify the best combination of the above mentioned fibres and dyes.

\section{Materials and Method}

\subsection{Material}

$100 \%$ cotton single jersey knitted fabric collected from a local fabric processing factory which is scoured and bleached with standard bleaching recipe. 100\% modal and lyocell yarn were collected from Lenze Bangladesh Office (origin Lenzing AG, Austria). Later, these two yarns separately knitted in single jersey structure by the single jersey circular knitting machine. The areal density of all the three fabric is around $160 \mathrm{~g} / \mathrm{m}^{2}$. Both the bifunctional and polyfunctional reactive dye were collected from Huntsman under the brand name Novacron Brilliant Red FN-3GL (CI Reactive Red 282) and Avitera Cardinal SE (CI Reactive Red 286). The others chemicals used in this experiment e.g. wetting agent, sequestering agent and detergent were collected from a local chemical's supplier whereas Glauber's salt, sodium hydroxide and sodium carbonate used in this study was lab grade chemical from Merck, Germany. The dyeing was carried out in Ahiba IR sample dyeing machine, Datacolor, USA.

\subsection{Method}

All the three fabrics (cotton, modal and lyocell) were pretreated according to recipe Table 1 (combined scouring-bleaching recipe for cotton) and Table 2 (mild scouring for modal and lyocell). As both the modal and lyocell are regenerated cellulosic fibres they do not possess any natural colour like cotton, So, no bleaching is required in these cases whereas mild scouring is sufficient to remove the possible dust, dirt or spin finish chemicals adhere on these two fibres. Then 
these three fabric were dyed with bifunctional (NOVACRON Brilliant Red FN-3GL) and polyfunctional (Avitera Cardinal SE) reactive dyes according to the recipe suggested by the suppliers in 4 different shades (1\%, $2 \%, 3 \%$ and $4 \%)$ Table 3 and Table 4 respectively. The concentration of residual dyebath liquor was determined by the absorbance value obtained from transmittance measurement system of spectrophotometer (Brand name: Datacolor Model: SF-650) using Beer-Lambert's law [6]. The exhaustion\% of dye in each dyeing is calculated from the Equation (1).

$$
\text { Exhaustion } \%=\frac{C_{0}-C_{t}}{C_{0}} \times 100
$$

where $C_{0}$ is the initial dye concentration and $C_{t}$ is the concentration of dye after a certain dyeing time [7].

The K/S of dyed fabric before and after wash were also measured by the reflectance measurement system of the above mentioned machine. Using these data, Fixation\% was calculated from the following Equation (2).

$$
\text { Fixation Efficiency }=\frac{[\mathrm{K} / \mathrm{S}]_{a}}{[\mathrm{~K} / \mathrm{S}]_{b}}
$$

where $[\mathrm{K} / \mathrm{S}] \mathrm{a}$ means $\mathrm{K} / \mathrm{S}$ value taken after washing off the sample and $[\mathrm{K} / \mathrm{S}] \mathrm{b}$ means $\mathrm{K} / \mathrm{S}$ value taken before washing off the sample according to recipe mentioned in Table 5.

Then fixation is measured from the formula mentioned in Equation (3).

$$
\text { Fixation } \%=\text { Exhaustion } \% \times \text { Fixation efficiency }
$$

Beside these, bursting strength according to ISO 13938-1:1999 method (measured by Hydraulic Burst Tester, Laboratory Supply Company, Germany), Pilling resistance according to SN 198-525 method (assessed by Martindale Pilling tester, SDL International, UK) and colour fastness to wash according to ISO 105-C06 C2S method (washing is performed by Gyrowash, James H. Heal, UK) was observed for all the dyed samples.

Table 1. Recipe of combined scouring and bleaching of cotton fabric.

\begin{tabular}{cc}
\hline Chemicals & Amount \\
M:L & $1: 15$ \\
Sequestering agent & $1 \mathrm{~g} / 1$ \\
Wetting agent & $1 \mathrm{~g} / 1$ \\
Sodium hydroxide & $2.5 \mathrm{~g} / 1$ \\
Detergent & $1 \mathrm{~g} / 1$ \\
Hydrogen peroxide (35\%) & $4 \mathrm{~g} / 1$ \\
Peroxide stabilizer & $1 \mathrm{~g} / 1$ \\
pH & $10.5-11$ \\
Temperature & $90^{\circ} \mathrm{C}-95^{\circ} \mathrm{C}$ \\
Time & $45 \mathrm{~min}$
\end{tabular}


Table 2. Recipe of scouring process of modal and lyocell.

\begin{tabular}{cc}
\hline Chemicals & Amount \\
\hline M:L & $1: 15$ \\
Sequestering agent & $1 \mathrm{~g} / 1$ \\
Wetting agent & $1 \mathrm{~g} / 1$ \\
Sodium Carbonate & $1 \mathrm{~g} / 1$ \\
Detergent & $2 \mathrm{~g} / 1$ \\
Temperature & $75^{\circ} \mathrm{C}$ \\
Time & $30 \mathrm{Min}$ \\
\hline
\end{tabular}

Table 3. Dyeing recipe with bifunctional reactive dye.

\begin{tabular}{ccccc}
\hline Chemicals & Amount \\
\hline M:L & $1 \%$ & $2 \%$ & $3 \%$ & $4 \%$ \\
Dyes & 35 & 40 & 50 & 55 \\
Glauber's salt & 10 & 12 & 14 & 16 \\
Soda ash & & $1 \mathrm{~g} / 1$ & \\
Wetting agent (g/l) & & $10.5 \pm 0.3$ & \\
Sequestering agent $(\mathrm{g} / \mathrm{l})$ & & & \\
pH & & & \\
Temperature & & \\
Time & & \\
\end{tabular}

Table 4. Dyeing recipe with polyfunctional reactive dye.

\begin{tabular}{ccccc}
\hline Chemicals & Amount \\
M:L & & $1: 10$ & \\
Dyes & $1 \%$ & $2 \%$ & $3 \%$ & $4 \%$ \\
Glauber's salt & 25 & 30 & 35 & 40 \\
Soda ash & 10 & 12 & 14 & 16 \\
Wetting agent (g/l) & & $1 \mathrm{~g} / \mathrm{l}$ & \\
Sequestering agent (g/l) & & $10.5 \pm 0.3$ & \\
pH & & $60^{\circ} \mathrm{C}$ \\
Temperature & $45 \mathrm{~min}$ \\
Time & \\
\end{tabular}

Table 5. Wash-off recipe.

\begin{tabular}{cc}
\hline Chemicals & Amount \\
\hline M:L & $1: 40$ \\
Time & 10 minutes \\
Temperature & $90^{\circ} \mathrm{C}$ \\
Detergent & $2 \mathrm{~g} / 1$ \\
\hline
\end{tabular}




\section{Result and Discussion}

\subsection{Exhaustion $\%$ and Fixation $\%$}

The exhaustion\% of bifunctional reactive dye in cotton, modal and lyocell is greater than that of polyfunctional reactive dye (Figures 1-3). But a significant amount of bifunctional reactive dye was lost in the effluent during wash off process which made a significant difference in fixation\%. In case of all three cellulosic fibres dyeing with polyfunctional reactive dye showed more than $90 \%$ fixation of the exhausted dye. But the overall fixation of the applied dye is less than that of bifunctional reactive dye. It was observed that polyfunctional reactive dye showed better fixation\% in all the three cellulosic fibres dyed with darker shade i.e. more than $3 \%$ shade.

\subsection{Colour Fastness to Wash}

\subsubsection{Grey Scale Rating for Shade Change}

The grey scale rating shade change after the wash of the dyed sample according to ISO 105 C06 (C2S) method, all the dyed sample showed very good to excellent colour fastness against wash with the prescribe detergent mention the method Figure 4.

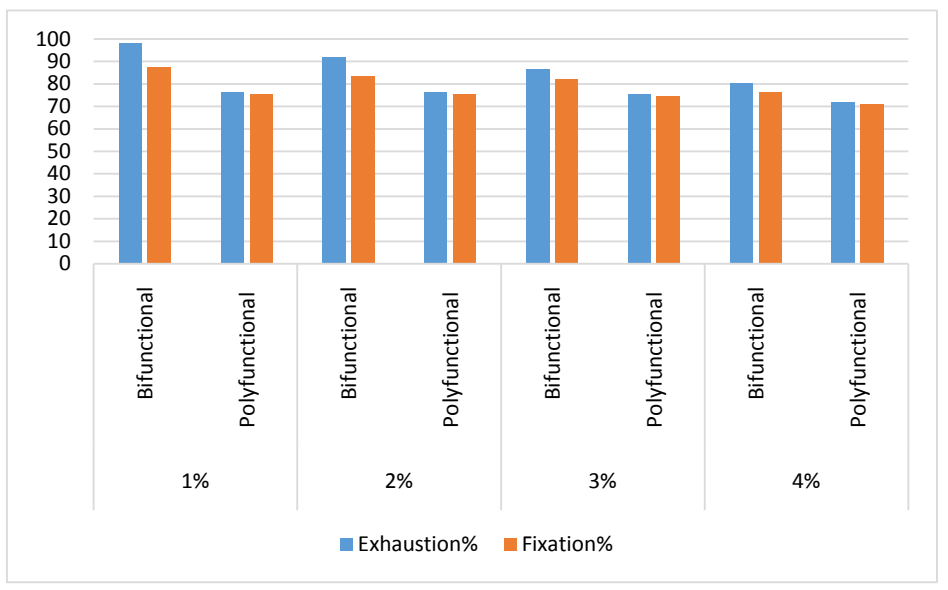

Figure 1. Exhaustion\% and Fixation\% of reactive dye in cotton.

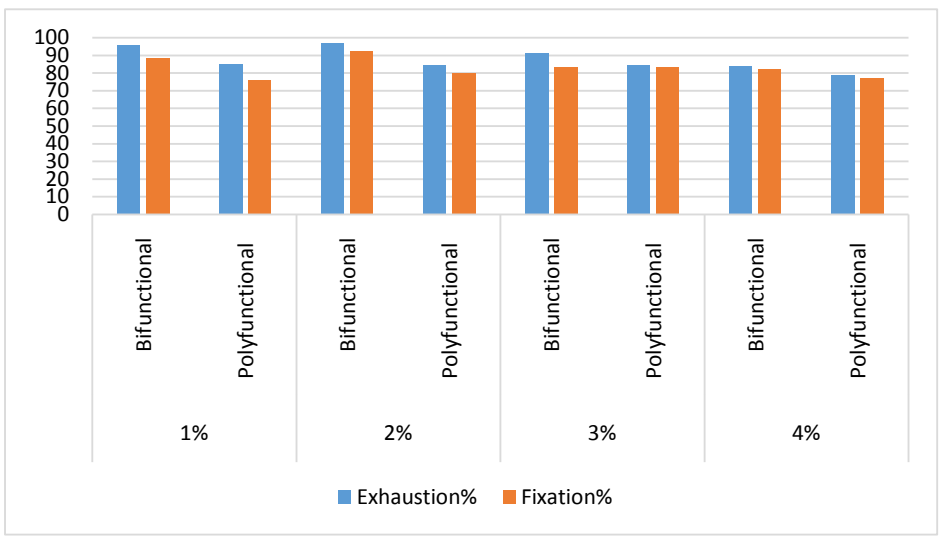

Figure 2. Exhaustion\% and Fixation\% of reactive dye in modal. 


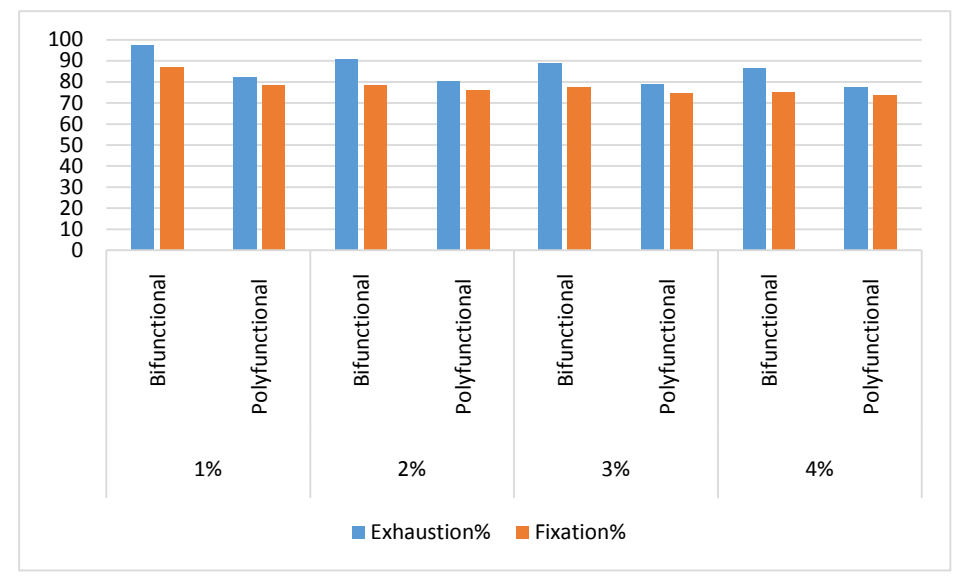

Figure 3. Exhaustion\% and Fixation\% of reactive dye in lyocell.

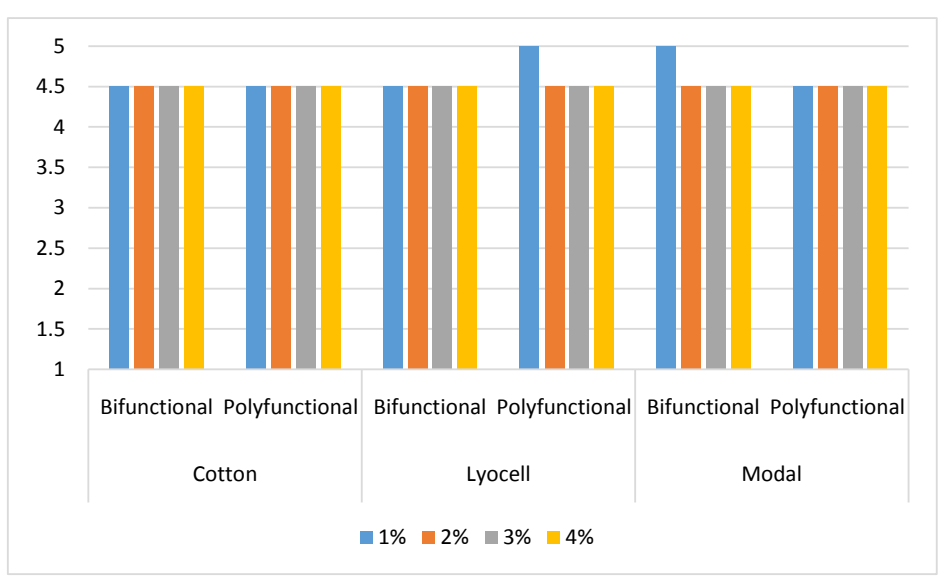

Figure 4. Grey scale rating for shade change dyeing with reactive dyes.

\subsubsection{Grey Scale Rating for Staining}

The DW type multifibre fabric used in this experiment contains six fibres namely Diacetate (DA), Bleached Cotton (BC), polyamide (PA), Polyester (PES), Acrylic (AC) and Wool (WL). It was observed very good to excellent resistant against staining for these six fibres in Table 6.

\subsection{Assessment of Pilling Resistance}

Cotton fabric showed better pilling resistance after 2000 cycle pilling according to SN 198 - 525 than modal and lyocell fabrics Figure 5. Lyocell showed lowest pilling resistance because of its structure. Lyocell fibre has better inter-molecular attraction but their lateral force of attraction is lower. This is the cause of fibrillation of lyocell and also lower pilling resistance. Lyocell dyed with polyfunctional dye showed slightly better pilling resistance than bifunctional dyes due to cross-linking action of polyfunctional dyes with cellulose [8].

\subsection{Comparison of Bursting Strength}

Cotton fabric showed higher bursting strength than lyocell and modal fabrics. Cotton fibre has higher Degree of Polymerization (up to 12,000) than lyocell and 
modal Figure 6. In wet condition, bursting strength of cotton increased due to formation of hydrogen bond that causes more uniform stress distribution which was responsible for the higher burst strength of wet cotton fabric in comparison with the dry sample. On the other hand, bursting strength of lyocell and modal fabrics decreased in wet condition because the softening action terminated with regenerated cellulosic fibres causing a considerable reduction in strength in going from dry to wet state Figure 7 [9].

Table 6. Grey scale rating for staining.

\begin{tabular}{|c|c|c|c|c|c|c|c|}
\hline \multirow[t]{2}{*}{ Sample } & \multirow[t]{2}{*}{ Shade $\%$} & \multicolumn{6}{|c|}{ Grey Scale Rating for Staining } \\
\hline & & DA & $\mathrm{BC}$ & $\mathrm{PA}$ & PES & $\mathrm{AC}$ & WL \\
\hline & $1 \%$ & 5 & $4-5$ & 5 & 5 & 5 & 5 \\
\hline $\begin{array}{l}\text { Bifunctional } \\
\text { reactive }\end{array}$ & $2 \%$ & 5 & 4 & 5 & 5 & 5 & 5 \\
\hline \multirow[t]{3}{*}{ dyed cotton } & $3 \%$ & 5 & 4 & 5 & 5 & 5 & 5 \\
\hline & $4 \%$ & 5 & $3-4$ & 5 & 5 & 5 & 5 \\
\hline & $1 \%$ & 5 & $4-5$ & 5 & 5 & 5 & 5 \\
\hline $\begin{array}{l}\text { Polyfunctional } \\
\text { reactive }\end{array}$ & $2 \%$ & 5 & $4-5$ & 5 & 5 & 5 & 5 \\
\hline \multirow[t]{3}{*}{ dyed cotton } & $3 \%$ & 5 & 4 & 5 & 5 & 5 & 5 \\
\hline & $4 \%$ & 5 & 4 & 5 & 5 & 5 & 5 \\
\hline & $1 \%$ & 5 & $4-5$ & 5 & 5 & 5 & 5 \\
\hline $\begin{array}{l}\text { Bifunctional } \\
\text { reactive }\end{array}$ & $2 \%$ & 5 & $4-5$ & 5 & 5 & 5 & 5 \\
\hline \multirow[t]{3}{*}{ dyed modal } & $3 \%$ & 5 & $4-5$ & 5 & 5 & 5 & 5 \\
\hline & $4 \%$ & 5 & 4 & 5 & 5 & 5 & 5 \\
\hline & $1 \%$ & 5 & 5 & 5 & 5 & 5 & 5 \\
\hline $\begin{array}{l}\text { Polyfunctional } \\
\text { reactive }\end{array}$ & $2 \%$ & 5 & $4-5$ & 5 & 5 & 5 & 5 \\
\hline \multirow[t]{3}{*}{ dyed modal } & $3 \%$ & 5 & $4-5$ & 5 & 5 & 5 & 5 \\
\hline & $4 \%$ & 5 & 4 & 5 & 5 & 5 & 5 \\
\hline & $1 \%$ & 5 & $4-5$ & 5 & 5 & 5 & 5 \\
\hline $\begin{array}{l}\text { Bifunctional } \\
\text { reactive }\end{array}$ & $2 \%$ & 5 & $4-5$ & 5 & 5 & 5 & 5 \\
\hline \multirow[t]{3}{*}{ dyed lyocell } & $3 \%$ & 5 & 4 & 5 & 5 & 5 & 5 \\
\hline & $4 \%$ & 5 & 4 & 5 & 5 & 5 & 5 \\
\hline & $1 \%$ & 5 & $4-5$ & 5 & 5 & 5 & 5 \\
\hline $\begin{array}{l}\text { Polyfunctional } \\
\text { reactive }\end{array}$ & $2 \%$ & 5 & $4-5$ & 5 & 5 & 5 & 5 \\
\hline \multirow[t]{2}{*}{ dyed lyocell } & $3 \%$ & 5 & 4 & 5 & 5 & 5 & 5 \\
\hline & $4 \%$ & 5 & 4 & 5 & 5 & 5 & 5 \\
\hline
\end{tabular}




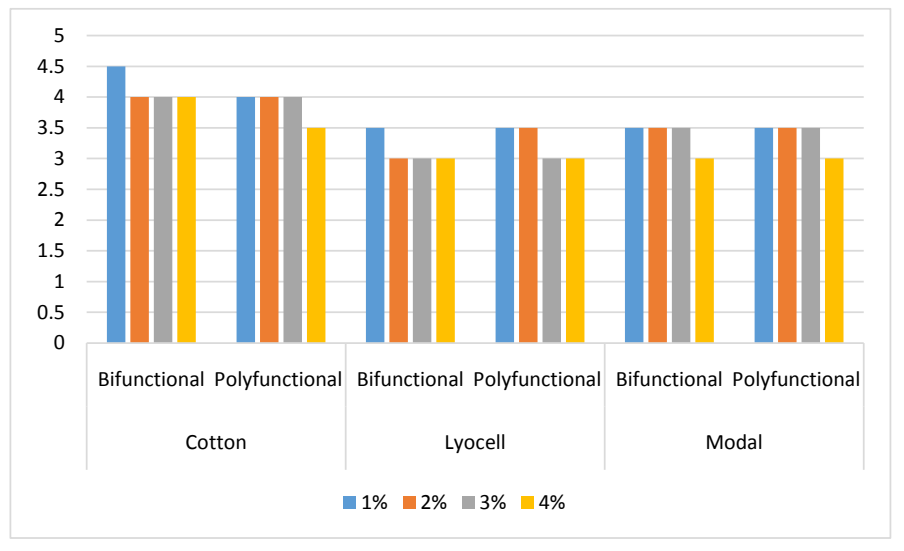

Figure 5. Pilling resistance rating.

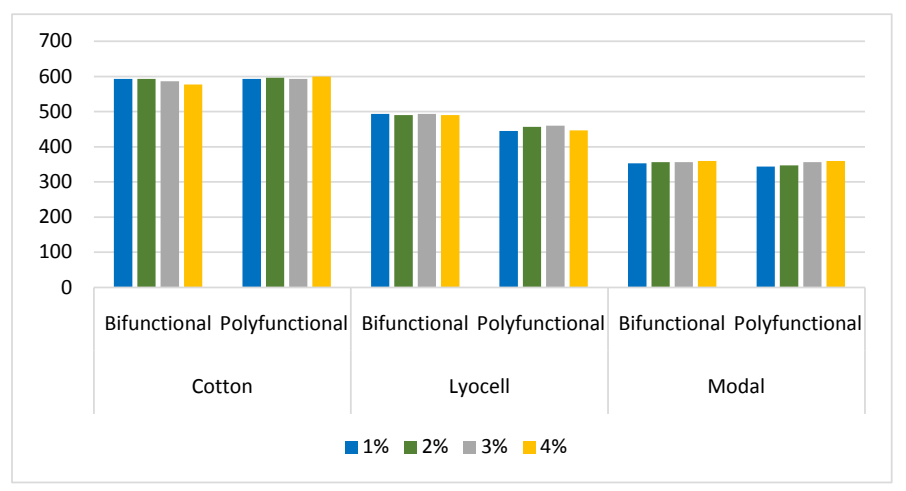

Figure 6. Bursting strength at dry condition.

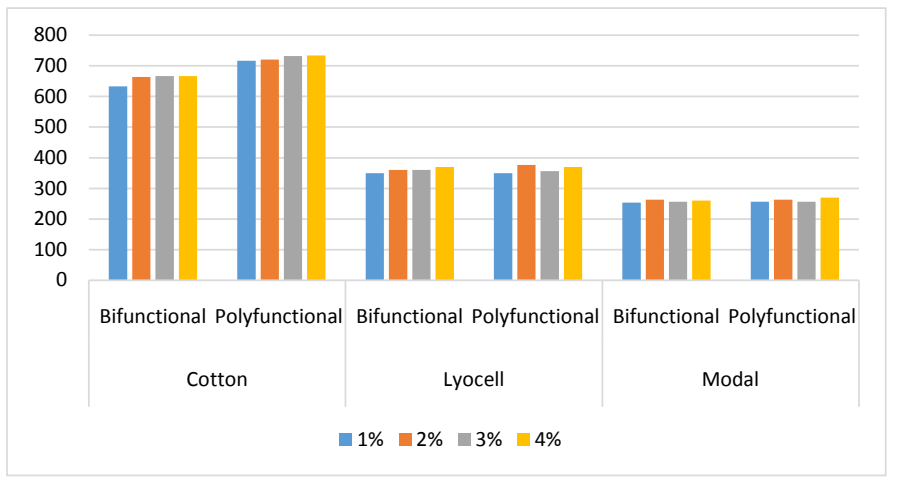

Figure 7. Bursting strength at wet condition.

\section{Conclusion}

In this paper, the performance of three cellulosic fibres dyed with both bifunctional and polyfunctional was evaluated. Bifunctional reactive dyes are applying on cotton for many decades. Researchers are continuously trying to improve its dyeing performance as a significant portion of applied dye is wasted during wash off process. It was observed that exhaustion\% of bifunctional reactive dye was relatively higher than that of polyfunctional reactive dye. But the difference between exhaustion\& and fixation\% is quite less in case of polyfunctional dye for all the three cellulosic fibres which indicates most of the exhausted polyfunc- 
tional reactive dye was fixed in fibre resulting colour fastness to wash good to excellent. Moreover pilling resistance lyocell dyed with polyfunctional reactive dye show better result to some extent than the bifunctional reactive dye. Bursting strength was not affected by the types of reactive for any cellulosic fibres. It can be concluded that polyfunctional reactive dye showed promising dyeing performance than traditional bifunctional reactive dye.

\section{Conflicts of Interest}

The author declares no conflicts of interest regarding the publication of this paper.

\section{References}

[1] Sreenivasa Murthy, H.V. (2018) Introduction to Textile Fibres. WPI, India. https://doi.org/10.1201/b20597

[2] Woodings, C. (2001) A Brief History of Regenerated Cellulosic Fibres. Regenerated Cellulose Fibres, Woodhead Publishing, UK, 1-21. https://doi.org/10.1533/9781855737587.1

[3] Yusuf, M., Shabbir, M. and Mohammad, F. (2017) Natural Colorants: Historical, Processing and Sustainable Prospects. Natural Products and Bioprospecting, 7, 123-145. https://doi.org/10.1007/s13659-017-0119-9

[4] Lewis, D.M. (2014) Developments in the Chemistry of Reactive Dyes and Their Application Processes. Coloration Technology, 130, 382-412.

https://doi.org/10.1111/cote.12114

[5] Annen, O., Gerber, H. and Seuthe, B. (1992) Dyeing Behaviour of Viscose and Modal Fibres Compared with That of Cotton. Journal of the Society of Dyers and Colourists, 108, 215-218. https://doi.org/10.1111/j.1478-4408.1992.tb01445.x

[6] McDonald, R. (1997) Colour Physics for Industry. Society of Dyers and Colourists, UK.

[7] Park, J. and Shore, J. (2004) Practical Dyeing. Society of Dyers \& Colourists., UK.

[8] Syed, U. (2010) The Influence of Woven Fabrics Structures on the Continuous Dyeing of Lyocell Fabrics with Reactive Dyes. Ph.D Thesis, Heriot-Watt University, Scottland.

[9] Hall, M.E., Horrocks, A.R. and Seddon, H. (1999) The Flammability of Lyocell. Polymer Degradation and Stability, 64, 505-510.

https://doi.org/10.1016/S0141-3910(98)00202-X 